\title{
Penile Cancer pN1 TNM Finding v7
}

National Cancer Institute

\section{Source}

National Cancer Institute. Penile Cancer pN1 TNM Finding v7. NCI Thesaurus. Code C89179.

Penile cancer with metastasis in a single ing uinal lymph node. (from AJCC 7th Ed.) 